H. Benbouhenni, S. Lemdani

\title{
COMBINING SYNERGETIC CONTROL AND SUPER TWISTING ALGORITHM TO REDUCE THE ACTIVE POWER UNDULATIONS OF DOUBLY FED INDUCTION GENERATOR FOR DUAL-ROTOR WIND TURBINE SYSTEM
}

\begin{abstract}
Aim. This work presents the amelioration of direct power control using synergetic-super twisting algorithms for asynchronous generators integrated into dual-rotor wind turbine systems. Method. The main role of the direct power control is to control the active and reactive powers and reduce the harmonic distortion of stator current of asynchronous generator for variable speed dual-rotor wind turbine systems. The traditional strategy is more attractive due to its high efficiency and simple algorithm. Super twisting algorithms are a non-linear command strategy; characterized by robustness against the parameters change or disturbances, it gives a good power quality under different conditions such as changing generator parameters. Novelty. Synergetic-super twisting algorithms are designed. Synergetic-super twisting algorithms construction is based on synergetic command and super twisting algorithms in order to obtain a robust control strategy and a fast system with acceptable precision. We use in our study a $1.5 \mathrm{MW}$ asynchronous generator integrated to dual-rotor wind turbine system in order to regulate the active and reactive powers. Results. As shown in the results figures using synergetic-super twisting algorithms the ameliorate performances especially minimizes the torque, active and reactive power undulations, and reduces harmonic distortion of stator current (THD = $0.19 \%)$ compared to traditional strategy. References 40, tables 2, figures 28.
\end{abstract}

Key words: super twisting algorithm, synergetic command, asynchronous generator, direct active and reactive power command.

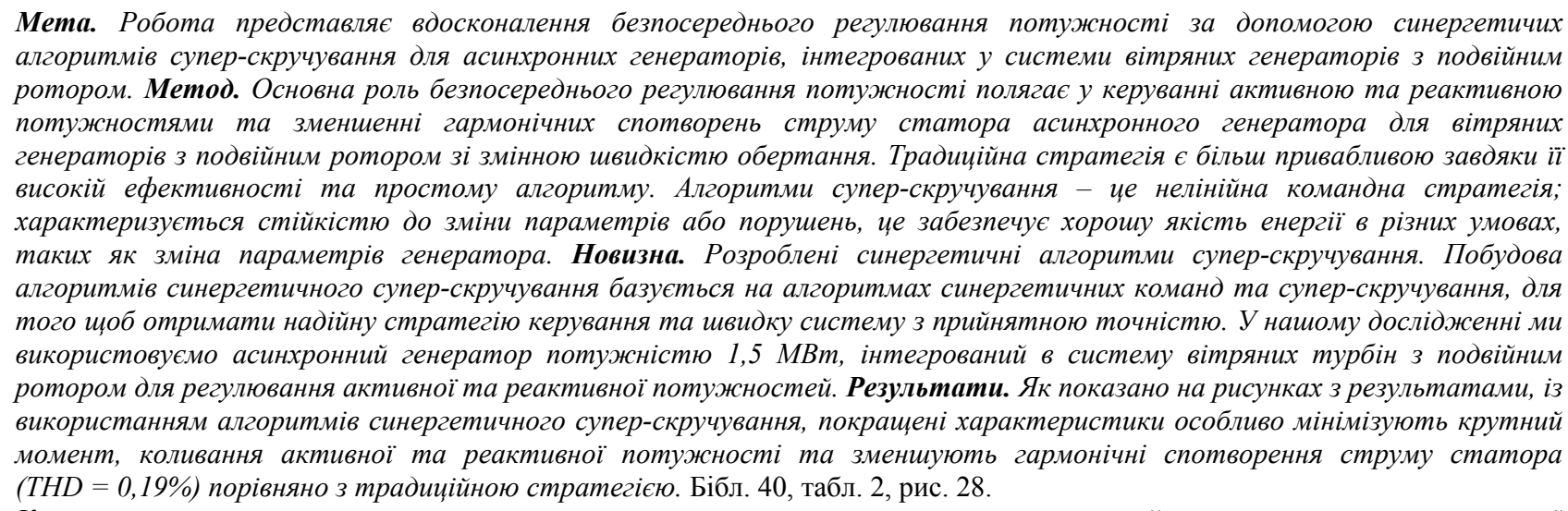
Ключові слова: алгоритм супер-скручування, синергетична команда, асинхронний генератор, команда прямої активної та реактивної потужності.

Introduction. Nowadays, the increasing demand for electrical energy, its sources and the ever-increasing consumption has allowed more attention to be given to the design of commands and techniques through which high-quality, undulations-free energy can be obtained. Also, the global warming crisis has created more competition between countries and university researchers. On the other hand, and the use of oil is no longer an option because it causes an increase in global warming and thus exacerbates the global crisis. Endangering human health and social stability for the sake of primary services such as electricity grids, transportation and communication systems, and the production of goods does not exist without thinking of a way to reduce global warming and emissions into the atmosphere.

In the field of electric power generation, the use of wind energy and renewable sources is essential to reduce the greenhouse effect. For these reasons, it has been suggested to use wind energy in generating electric power, and the most important advantage is that it is free to generate electricity and reduce the emission of toxic gases in to the atmosphere, regardless of the negative aspects of using wind energy. This source prevents the risks of increasing global warming. On the other hand, the financial cost and the difficulty of implementation and control increase the possibility of not using wind energy, which could cause an increase in the demand for the use of non-renewable resources such as gas, for example, and thus an increase in the emission of $\mathrm{CO}_{2}$. Also, an increase in the cost of producing electrical energy, which leads to imposing taxes on electric energy consumption.

In the field of electric power generation, there are several electric generators used in generating electric energy using wind energy, for example, asynchronous and synchronous generators.

In our work, we will study the asynchronous generator (ASG) in generating electrical energy using a renewable source. Among the advantages of using an ASG is that it is solid and simple to command, unlike other generators [1]. In the industrial field, there are several types of command methods for electrical machines, especially electrical generators. Among these methods, we mention direct torque command [2], direct power command [3], hybrid command [4], and artificial intelligence use command [5]. Direct power command is

(C) H. Benbouhenni, S. Lemdani 
among the other methods used. This method has its pros and cons just like the other methods, an easy and uncomplicated way, all generators can be converted. Among its disadvantages, we find ripples in the active and reactive powers, which are the most prominent negatives that characterized them. There are several scientific studies in this field that have concluded that fluctuations in reactive and active power oscillations can be reduced by using modern technologies such as fuzzy logic [6], neural networks [7], neuro-fuzzy command [8], sliding mode control (SMC) technique [9], genetic algorithm [10], synergetic control (SYC) [11], super twisting algorithm (STA) [12], etc.

The sliding mode is a particular operating mode of variable structure systems. It is considered one of the simplest approaches for controlling nonlinear systems and systems with an imprecise model. This command has the following characteristics [13]:

- the response of the system is insensitive and robust to variations in certain parameters and the effects of load disturbances and disturbances;

- it suffices to know a terminal for $u(t)$ which simplifies the adjustment;

- it choice of the switching surface is fairly free;

- the order is softened by the presence of the equivalent order, which can be deleted at the cost of an increase of $u(t)$.

The sliding surface $S$ is a scalar function such that the variable to be adjusted slides on this surface. The purpose of the command is to keep the surface at zero. The main drawback of the command in higher-order sliding mode lies in the need to know the state variables and their derivatives. A sliding regime of order $r$ (noted $r$-sliding) acts on the surface and its $(r-1)$ first successive derivatives to time. The objective is to force the system to evolve not only on the surface but also on its $(r-1)$ first successive derivatives and to keep the sliding set at zero:

$$
S=\dot{S}=\ddot{S}=\ldots=\left(S^{r-1}\right)=0,
$$

with $r$ designates the relative degree of the system, and its $(r-1)$ first successive derivatives with respect to time.

STA algorithm is a kind of high-order SMC technique. It is characterized by simplicity and durability compared to some techniques. This method was proposed by the Levant in 1993 [14]. This method has been applied in several fields [15-19]. Furthermore, the SYC method is also applied. It tries to overcome the problem of controlling the power converter by using the internal dynamic characteristics of the system, the most important advantages of this approach are order reduction, decoupling design procedure, and insensitivity to parameter changes [20]. On the other hand, this method reduces the vibrations present in the sliding command and improves the stability of the system [21].

A new nonlinear control has been proposed in this paper. This proposed nonlinear control is based on STA algorithms and synergetic control theory.

The aim of this work is the improve the performance of direct reactive and active power control (DRAPC) using synergetic-super twisting algorithms (SYSTA) for ASG-based dual-rotor wind power (DRWP) system under variable speed wind and also to reduce fluctuations in torque, current and active power.

This method is called SYSTA, and it is the product of a marriage of properties of both synergetic control and STA algorithms. This method can be applied to all controls without exception, and it has provided very satisfactory results compared to the classical method.

Model of DRWP. Traditionally, the applied systems of wind turbine systems can be classified into variable speed (VS) and fixed speed turbines (FST). The VS turbine systems (VSTSs) are now more often applied than the systems with FST. The main advantages of VSTSs are: increasing the production of wind power, the ability to achieve maximum power conversion efficiency, and reduction of mechanical stresses. On the other hand, the DRWP is a wind turbine used to generates electrical power. The DRWP system has been proposed as new wind energy, as shown in Fig. 1.

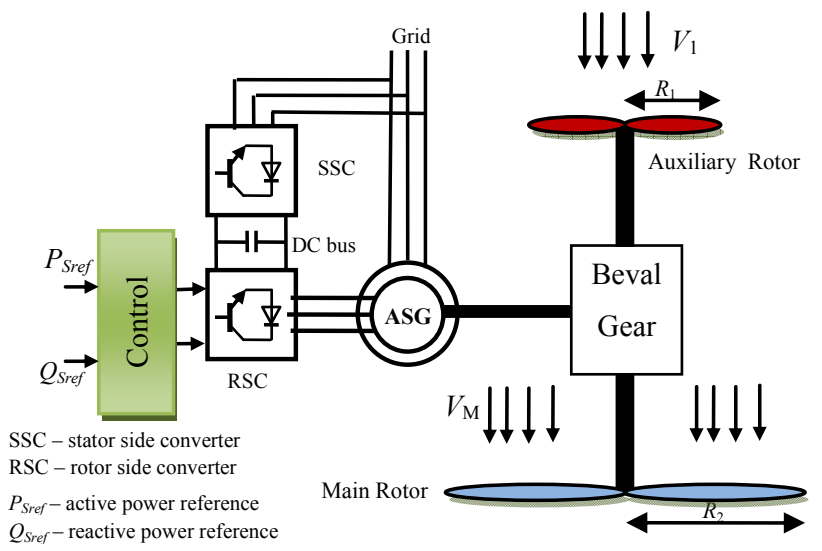

Fig. 1. Block diagram of DRWP with a ASG is [22]:

The aerodynamic torque of the auxiliary rotor

$$
T_{A}=\frac{1}{2 \cdot \lambda_{A}^{3}} \cdot \rho \cdot \pi \cdot R_{A}^{5} \cdot C_{p} \cdot w_{A}^{2}
$$

and aerodynamic torque of the main rotor is:

$$
T_{M}=\frac{1}{2 \cdot \lambda_{M}^{3}} \cdot \rho \cdot \pi \cdot R_{A}^{5} \cdot C_{p} \cdot w_{M}^{2}
$$

where $\lambda_{A}, \lambda_{M}$ are the tip speed ration of the auxiliary and main rotors; $R_{M}, R_{A}$ are the blade radius of the main and auxiliary rotors, $\rho$ is the air density; $w_{A}, w_{M}$ are mechanical speed of the auxiliary and main rotors; $C_{p}$ is the power coefficient

The tip speed ratio of the auxiliary rotor (AR) is:

$$
\lambda_{A}=\frac{w_{A} \cdot R_{A}}{V_{1}}
$$

and the tip speed ratio of the main rotor (MR) is:

$$
\lambda_{M}=\frac{w_{M} \cdot R_{M}}{V_{M}},
$$

where $V_{M}$ is the speed of the unified wind on main rotor and $V_{1}$ is the wind speed on an auxiliary wind turbine (AWT).

The total aerodynamic torque of DRWP $\left(T_{T}\right)$ is the sum of AR torque $\left(T_{A}\right)$ and the MR torque $\left(T_{M}\right)$ :

$$
T_{D R W T}=T_{T}=T_{A}+T_{M} \text {. }
$$


The wind speed on the auxiliary and main turbines is the essential element to calculating the tip speed ratio. Equation (6) represents the wind speed in the main turbine [23]

$$
V_{x}=V_{1}\left(1-\frac{1-\sqrt{\left(1-C_{T}\right)}}{2} \cdot\left(1+\frac{2 \cdot x}{\sqrt{1+4 \cdot x^{2}}}\right)\right),
$$

where $x$ is the non-dimensional distance from the auxiliary rotor disk, $V_{x}$ is the velocity of the disturbed wind between rotors at point $x ; C_{T}$ is the trust coefficient, which is taken 0.9 [24]. The distance between the main and the auxiliary turbines is $15 \mathrm{~m}$.

The $C_{p}$ is given as:

$$
C_{p}(\lambda, \beta)=\frac{1}{\lambda+0.08 \beta}-\frac{0.035}{\beta^{3}+1},
$$

where $\lambda$ is the tip speed ratio; $\beta$ is pitch angle.

Synergetic-super twisting algorithm. A system with variable structure is a system whose structure changes during its operation, it is characterized by the choice of a structure and switching logic. This choice allows the system to switch from one structure to another at any time. Moreover, such a system can have new properties which do not exist in every structure.

In the control of systems with variable structure by sliding mode, the state trajectory is brought to a surface, then using the switching law, it is forced to stays in the vicinity of this surface, this latter is called surface sliding movement and the movement along which occurs is called sliding movement [25].

During the last century, many nonlinear methods have been proposed for controlling electrical machines. Among the most famous of them we find control by slip control and this is due to the simplicity of the method and durability. Recently a new theory has appeared called synergetic control [26]. This method is more simple and uncomplicated based on the area derivation calculation. The SYC theory is one of the new methods of robust control [27]. It is characterized by its external disturbance rejection capabilities, simplicity of design, and the global stability assurance of the system [28]. The SYC method is a strategy quite close to the SMC strategy in the sense that it forces the system to evolve with a dynamic pre-chosen by the designer. This novel technique does not require the linearization of the model and explicitly uses a nonlinear model for the synthesis of the control. Also, the SYC method eliminates more the chattering phenomenon compared than the SMC strategy [29].

Equation (8) illustrates the principle of the SYC method, as it depends on the derivation of the surface

$$
T \dot{S}(x)+S(x)=0,
$$

where $T>0$ is a speed of convergence of surfaces to the intersection of manifolds $S=0$.

The following to ensure the stability of SYC method: $S(0)=0, S(x) x>0$ for all $x \neq 0$.

The solution of Eq. (8) is given by:

$$
S(t)=\dot{S}_{0} e^{t / T}
$$

Basically, STA design follows two steps to implement. In the STA strategy, the command input applies on the second-order derivative of the sliding surface, reverses the SMC it acts on the first derivative of the sliding surface [30]. The command input of the STA method comprises two inputs as (10)

$$
w(t)=w_{1}+w_{2}
$$

where:

$$
\begin{gathered}
w_{1}(t)=\lambda_{1} \sqrt{|S|} \cdot \operatorname{sign}(S), \\
w_{2}(t)=\lambda_{2} \int \operatorname{sign}(S) d t .
\end{gathered}
$$

The designed strategy has the same objective as the STA and SYC method, it will force the state trajectory to operate on the surface $S=0$. The surface is selected according to system constraints. The proposed method is a combination of the STA and SYC method. This proposed controlled named SYSTA algorithm, where this controller is a simple structure and more robust compared to SYC and STA techniques. Our goal for this controller is to minimize more and more the active and reactive power undulations.

Equation (13) illustrates the principle of the SYSTA controllers

$$
u(t)=u_{1}(t)+u_{2}(t)
$$

where the $u_{1}(t)$ and $u_{2}(t)$ represent the STA method and the synergetic command, respectively

$$
\begin{gathered}
u_{1}(t)=\alpha_{1} \sqrt{|S(t)|} \cdot \operatorname{sign}(S(t))+\alpha_{2} \int \operatorname{sign}(S(t)) d t, \\
u_{2}(t)=\alpha \frac{d S(t)}{d t}+S(t) .
\end{gathered}
$$

The command input of the designed SYSTA method is obtained as (16)

$$
\begin{aligned}
& u(t)=\alpha_{1} \sqrt{|S(t)|} \cdot \operatorname{sign}(S(t))+\alpha_{2} \int \operatorname{sign}(S(t)) d t+ \\
& +\alpha \frac{d S(t)}{d t}+S(t),
\end{aligned}
$$

where the tuning constants $\alpha, \alpha_{1}$ and $\alpha_{2}$ are used to tune the SYSTA technique to smoothen the regulator.

This is the design process using the SYSTA controller for the DRAPC method. On the other hand, Fig. 2 shows a block diagram representation of the SYSTA technique for DRAPC command in DRWP systems.

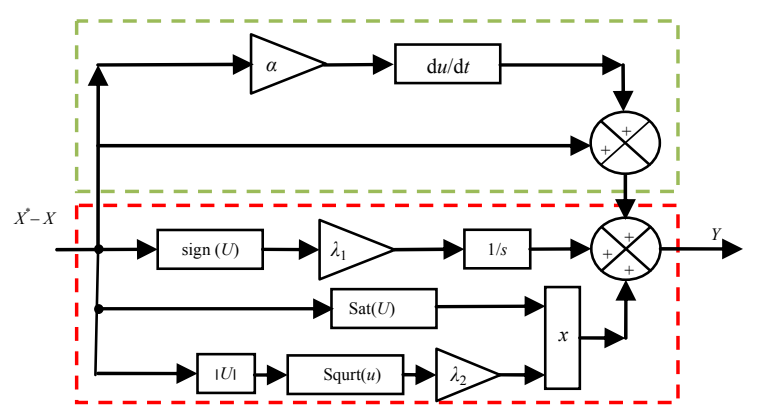

Fig. 2. Structure of the command law of the proposed SYSTA technique

This designed command is used in this work for minimizing electromagnetic torque, rotor current, active power, reactive power, and rotor flux undulations in an ASG-based DRWP system using the DRAPC method which the inverter was controlled by the modified space vector modulation (SVM) technique.

DRAPC technique. The principle of the DRAPC strategy is the direct regulation of the reactive and active 
powers of the generator, by applying different voltage vectors to the inverter, which determines its state. The two controlled variables are active and reactive powers which are usually controlled by hysteresis comparators. The idea is to keep the reactive power quantities and the active powers within these hysteresis bands. The output of these regulators determines the optimum voltage vector to be applied at each switching instant [31].

This technique involves the operation of the inverter at two standard levels with a variable control frequency which is sometimes high and incompatible with high power applications due to the level of switching losses.

Two command techniques have been used to implement DRAPC commands:

- command by a lookup table;

- command by a SVM technique.

The purpose of a DRAPC strategy is to keep the reactive power and active power modulus within the hysteresis bands by choosing the output voltage of the inverter. When the active power or reactive power modulus reaches the upper or lower limit of the hysteresis, an appropriate voltage vector is applied to bring the relevant magnitude back from its hysteresis band. To study the basic principle of the main direct control strategies of the ASG, it is essential to be able to characterized the behavior of the main variables which govern the power state of the generator, namely the reactive power and the active power. To this end, we will establish below rules of behavior of the reactive power and the active power on the scale of the sampling period, thus allowing the establishment of a relation between the application of a voltage vector and the direction of variation of these variables.

The basic structure of the DRAPC strategy is shown in Fig. 3, inverter command is instantaneous, which requires a very small sampling period.

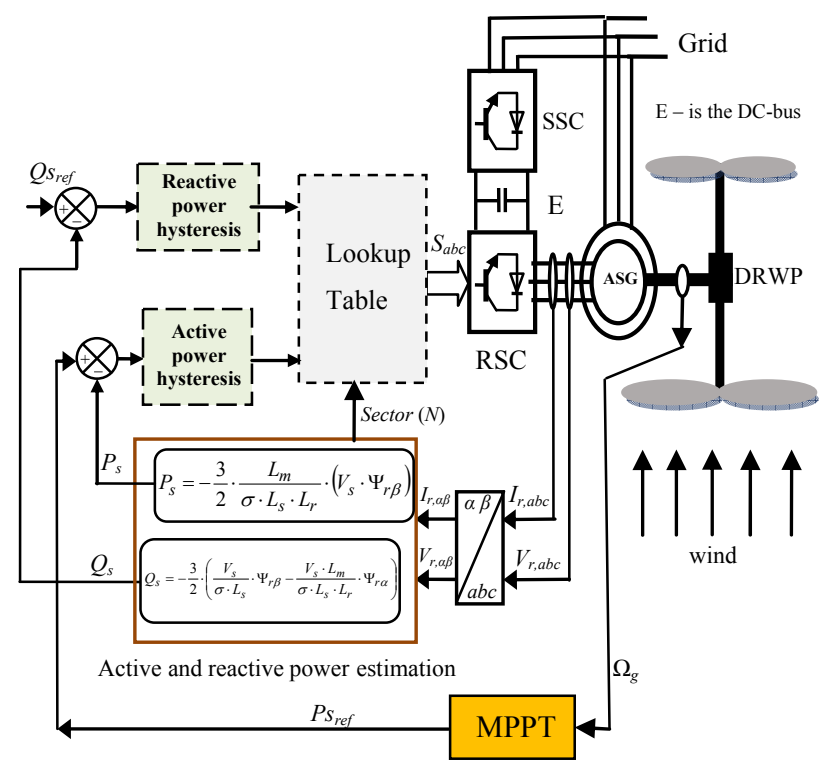

Fig. 3. Traditional DRAPC command technique

The principle is the direct regulation of the reactive and active powers of the ASG by applying the various voltage vectors of the rotor inverter, which rotor flux $\left(\Psi_{r}\right)$ determines its state. The two controlled variables are the active power and the reactive power which are controlled by hysteresis regulators. In a DRAPC strategy, it is preferable to work with a high calculation frequency to reduce the reactive and active power oscillations caused by the regulators [32]. A voltage inverter achieves seven distinct positions in the phase plane, corresponding to the eight sequences of the voltage vector at the output of the rotor inverter [33].

The reactive power $Q_{s}$ is expressed as a function of the quadrature rotor flux and the direct rotor flux as follows:

$$
Q_{s}=-\frac{3}{2} \cdot\left(\frac{V_{s}}{\sigma \cdot L_{s}} \cdot \Psi_{r \beta}-\frac{V_{s} \cdot L_{m}}{\sigma \cdot L_{s} \cdot L_{r}} \cdot \Psi_{r \alpha}\right) .
$$

The active power command depends directly on the control of the rotation of the rotor flux vector.

$$
P_{s}=-\frac{3}{2} \cdot \frac{L_{m}}{\sigma \cdot L_{s} \cdot L_{r}} \cdot\left(V_{s} \cdot \Psi_{r \beta}\right) .
$$

The rotor flux $\Psi_{r}$ can be estimated from measurements of the stator current and voltage of the generator.

From the equation:

$$
\Psi_{r}=\int_{0}^{t}\left(V_{r}-R_{r} \cdot i_{r}\right) d t
$$

we obtain the components $\alpha$ and $\beta$ of the vector $\Psi_{r}$ :

$$
\left\{\begin{array}{l}
\Psi_{r \alpha}=\int_{0}^{t}\left(V_{r \alpha}-R_{r} \cdot i_{r \alpha}\right) d t ; \\
\Psi_{r \beta}=\int_{0}^{t}\left(V_{r \beta}-R_{r} \cdot i_{r \beta}\right) d t .
\end{array}\right.
$$

The rotor flux amplitude is given by:

$$
\Psi_{r}=\sqrt{\Psi_{r \alpha}^{2}+\Psi_{r \beta}^{2}},
$$

where

$$
\left|\overline{\Psi_{r}}\right|=\left|\overline{V_{r}}\right| / w_{r} .
$$

The rotor flux $\left(\theta_{r}\right)$ angle is calculated by:

$$
\theta_{r}=\operatorname{arctg}\left(\frac{\Psi_{r \beta}}{\Psi_{r \alpha}}\right)
$$

The estimation of the reactive power and the active power requires prior knowledge of the components of the current and those of the stator voltage. It is retained in the case of a nonlinear command applied to the ASG in particular and especially the command by DRAPC strategy.

Figure 4 shows the logic output deviation $H C_{p}$ of the controller following the evolution of the active power $\left(P_{s}\right)$ compared to the reference active power $\left(P s_{r e f}\right)$.

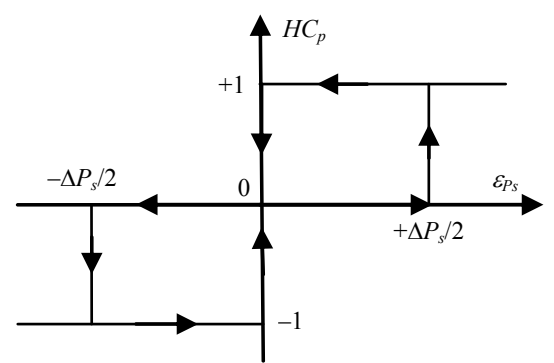

Fig. 4. Active power hysteresis comparator 
This corrector makes it possible to command the generator in both directions of rotation, either for a positive or negative active power.

The corrector output, presented by the Boolean variable $H C_{p}$ indicates directly whether the active power amplitude must be increased in absolute value $\left(H C_{p}=1\right)$ for a positive setpoint and $\left(H C_{p}=-1\right)$ for a negative setpoint, or reduced $\left(H C_{p}=0\right)$ this corrector allows a rapid decrease in active power.

This comparator is modeled by the following algorithm, such that $H C_{p}$ represents the output state of the comparator and $\Delta P_{s}$ the limit of the hysteresis band

$$
\begin{aligned}
& \text { if } E_{P S}<\Delta P_{s} \text { so } H C_{p}=1 \text {; } \\
& \text { if } 0 \leq E_{P s}<\Delta P_{s} \text { and } \frac{d E_{P_{S}}}{d t}>0 \text { so } H C_{p}=0 \text {; } \\
& \text { if } 0 \leq E_{P_{S}}<\Delta P_{S} \text { and } \frac{d E_{P_{S}}}{d t}<0 \text { so } H C_{p}=1 \text {; } \\
& \text { if } E_{P S}<-\Delta P_{S} \text { so } H C_{p}=-1 \text {; } \\
& \begin{array}{l}
\text { if }-\Delta P_{S} \leq E_{P S} \leq 0 \text { and } \frac{d E_{P S}}{d t}>0 \text { so } H C_{p}=0 \\
\text { if }-\Delta P_{S} \leq E_{P S} \leq 0 \text { and } \frac{d E_{P S}}{d t}<0 \text { so } H C_{p}=-1,
\end{array}
\end{aligned}
$$

where $E_{P_{S}}=P_{\text {Sref }}-P_{S}$.

Its purpose to keep the end of the reactive power $\left(Q_{s}\right)$ in a circular crown as shown in Fig. 5. The output of the corrector must indicate the direction of evolution of the modulus of $Q_{s}$, in order to select the corresponding voltage vector.

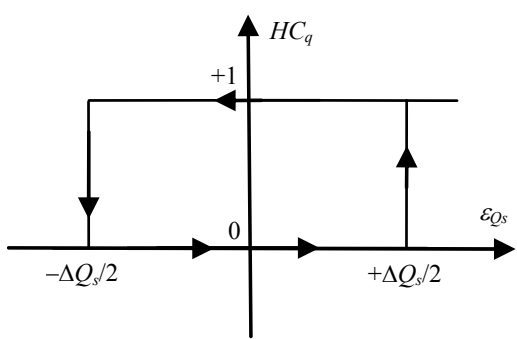

Fig. 5. Reactive power hysteresis comparator

For this, a simple two-level hysteresis corrector is ideal, and also allows very good dynamic performance to be obtained.

The output of the corrector is represented by a Boolean variable $\left(H C_{q}\right)$ and indicates directly whether the amplitude of the flow must be increased $\left(H C_{q}=1\right)$ or decreased $\left(H C_{q}=0\right)$ in order to maintain:

$$
\left|Q_{s}^{*}-Q_{s}\right| \leq \varepsilon_{Q s}=\Delta Q_{S},
$$

where $Q_{s}^{*}=Q_{\text {Sref }}$ is the reactive power reference; $\Delta Q_{s}$ is the corrector hysteresis width; $\varepsilon_{Q s}$ is half the width of the corrector hysteresis band.

The choice of the voltage vector to apply depends on the sign of the error between the reference reactive power $Q_{\text {Sref }}$ and the estimated reactive power

$$
\left\{\begin{array}{l}
H C_{q}=1 \text { for } E_{Q s}>\varepsilon_{Q s} \\
H C_{q}=0 \text { for } E_{Q s}<\varepsilon_{Q s} .
\end{array}\right.
$$

We can write like this:

$$
\left\{\begin{array}{l}
\text { if } E_{Q s}<\Delta Q_{s} \text { so } H C_{q}=0 ; \\
\text { if } 0 \leq E_{Q s} \leq \Delta Q_{s} \text { and } \frac{d E_{Q s}}{d t}>0 \text { so } H C_{q}=0 ; \\
\text { if } 0 \leq E_{Q s} \leq \Delta Q_{s} \text { and } \frac{d E_{Q s}}{d t}<0 \text { so } H C_{q}=1 ; \\
\text { if } E_{Q s}<-\Delta Q_{s} \text { so } H C_{q}=0 .
\end{array}\right.
$$

Indeed, if we introduce the difference $\Delta Q_{s}$, between the reference reactive power $\left(Q_{\text {Sref }}\right)$ and the estimated reactive power $\left(Q_{s}\right)$ in a two-level hysteresis comparator (see Fig. 5), it generates at its output the value $H C_{q}=+1$ to increase the reactive power and $H C_{q}=0$ to reduce it, this also allows obtaining a very good dynamic performance of the reactive power [34].

The choice of the voltage vector to apply depends on the sign of the error between the reference reactive power $\left(Q_{\text {Sref }}\right)$ and the estimated flux reactive power.

The Control Panel is built according to the state of the variables $H C_{q}$ and $H C_{p}$, and of the zone $\mathrm{Ni}$ of the position of $\Phi_{s}$. It therefore, takes the following form [35] from Table 1 .

Table 1

Traditional lookup table of DRAPC technique

\begin{tabular}{|c|c|c|c|c|c|c|c|}
\hline \multicolumn{2}{|c|}{$N_{i}$} & \multirow{2}{*}{1} & 2 & 3 & 4 & 5 & 6 \\
\hline$H C_{q}$ & $H C_{p}$ & & & & & & \\
\hline \multirow{3}{*}{1} & 1 & 5 & 6 & 1 & 2 & 3 & 4 \\
\cline { 2 - 8 } & 0 & 7 & 0 & 7 & 0 & 7 & 0 \\
\cline { 2 - 8 } & -1 & 3 & 4 & 5 & 6 & 1 & 2 \\
\hline \multirow{3}{*}{0} & 1 & 6 & 1 & 2 & 3 & 4 & 5 \\
\cline { 2 - 8 } & 0 & 0 & 7 & 0 & 7 & 0 & 7 \\
\cline { 2 - 8 } & -1 & 2 & 3 & 4 & 5 & 6 & 1 \\
\hline
\end{tabular}

where: $H C_{q}=0$ reduce the reactive power;

$H C_{q}=1$ increased the reactive power;

$H C_{p}=1$ increase the active power;

$H C_{p}=0$ reduce the active power;

$H C_{p}=-1$ maintain the active power.

DRAPC with synergetic STA control. Direct reactive and active power control has been known to produce a fast response and strong strategy over the electrical generators used in the production of electric current using wind energy. However, there are undulations in active power, torque, reactive power, and current. There are several theories and modern strategies that have been used to minimizes the fluctuations that occur in both active and reactive powers. Among these methods, we find: backstepping control, neural networks, neuro-fuzzy control, synergetic control, sliding mode control, and fuzzy logic.

In this paper, a nonlinear DRAPC of ASG is presented based on an SYSTA controller. The variation of rotor and stator resistance due to changes DRAPC controller by introducing errors in the estimated flux linkage, reactive and active powers. The use of the SYSTA strategy minimizes the risks of a risk in the resistance value of the ASG, which leads to a decrease in the undulations.

The DRAPC with SYSTA controllers (SYSTADRAPC) is a modification of the classical DRAPC strategy, where the switching table and hysteresis 
controllers, have been replaced by a space vector pulse width modulation (SVPWM) technique and SYSTA controllers as shown in Fig. 6. Both of them do not need advanced mathematical models. The DRAPC with SYSTA controller's goal is to control the active and reactive powers of the ASG. The active power is regulated by the quadrature axis voltage $V_{q r}{ }^{*}$, while the reactive power is regulated by the direct axis voltage $V_{d r}{ }^{*}$.

The sliding surfaces $S(x)$ representing the error between the measured and reference active and reactive powers are given by this relation:

$$
\begin{gathered}
S_{q}=Q_{\text {Sref }}-Q_{s} ; \\
S_{p}=P_{\text {Sref }}-P_{s} .
\end{gathered}
$$

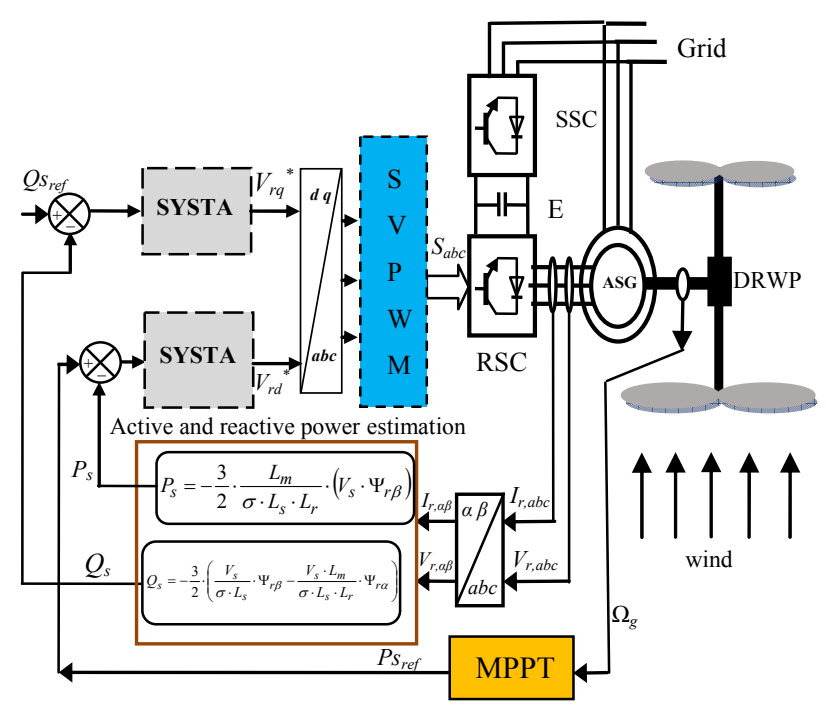

Fig. 6. DRAPC strategy with SYSTA controllers

Reactive and active power SYSTA controllers are used to influence respectively on the two rotor voltage components as in (30) and (31)

$$
\begin{aligned}
& V_{q r}^{*}=\alpha_{1} \cdot \sqrt{\left|S_{p}(t)\right|} \cdot \operatorname{sign}\left(S_{p}(t)\right)+ \\
& +\alpha_{2} \int \operatorname{sign}\left(S_{p}(t)\right)+\alpha \frac{d S_{p}(t)}{d t}+S_{p}(t) \\
& V_{d r}^{*}=\alpha_{1} \cdot \sqrt{\left|S_{q}(t)\right|} \cdot \operatorname{sign}\left(S_{q}(t)\right)+ \\
& +\alpha_{2} \int \operatorname{sign}\left(S_{q}(t)\right)+\alpha \frac{d S_{q}(t)}{d t}+S_{q}(t) .
\end{aligned}
$$

This proposed controller is implemented for a DRAPC technique based on the SYSTA controllers to obtain a minimum active power undulations and to minimize the chattering phenomenon. The controller structure for the SYSTA controllers for the reactive power and active power of the DRAPC technique are presented in Fig. 7 and Fig. 8, respectively.

Numerical simulations. The behavior of the structure of the proposed strategies, applied to a high power ASG (1.5 MW), is simulated under the Matlab / Simulink environment and the sampling time is $10^{-5} \mathrm{~s}$. The simulation is performed under the following conditions:

The hysteresis band of the reactive power comparator is, in this case, fixed at $\pm 0.05 \mathrm{VAR}$, and that of the active power comparator at $\pm 0.001 \mathrm{~W}$.

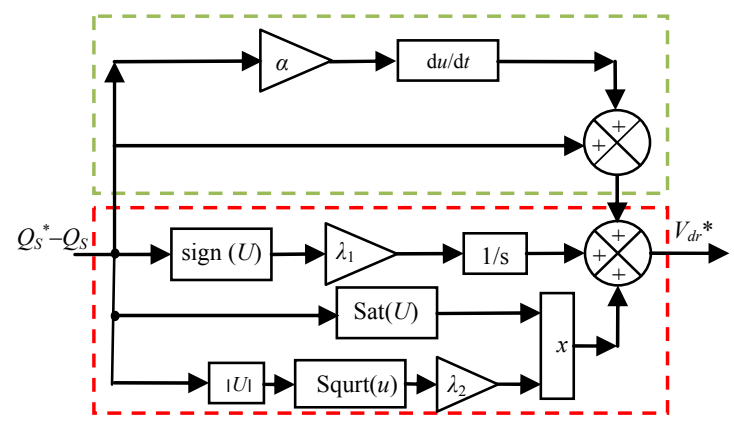

Fig. 7. SYSTA-reactive power controller

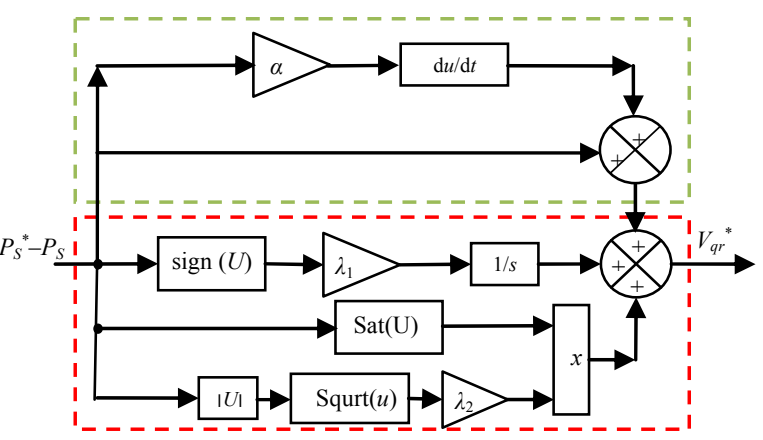

Fig. 8. SYSTA-active power controller

The ASG used in our study has the following parameters: two poles, $50 \mathrm{~Hz}, 380 / 696 \mathrm{~V}, P_{s n}=1.5 \mathrm{MW}$, $L_{m}=0.0135 \mathrm{H}, R_{s}=0.012 \Omega, J=1000 \mathrm{~kg} \cdot \mathrm{m}^{2}, R_{r}=0.021 \Omega$, $L_{s}=0.0137 \mathrm{H}, L_{r}=0.0136 \mathrm{H}$, and $f_{r}=0.0024 \mathrm{~N} \cdot \mathrm{m} / \mathrm{s}$ [36].

A. First test. This first test is the reference tracking test and the results obtained are shown in Fig. 9-18. Figure 9 shows the torque of the proposed and classical strategies. It can be seen, that the amplitudes of the torque depend on the value of the load active power.

Figures 11, 12 represent the active and reactive powers of both strategies. The reactive and active powers track almost perfectly their reference values. Figure 10 shows the current of both DRAPC techniques. It, therefore, confirms that the amplitudes of the currents depend on the value of the load active power and the state of the drive system.

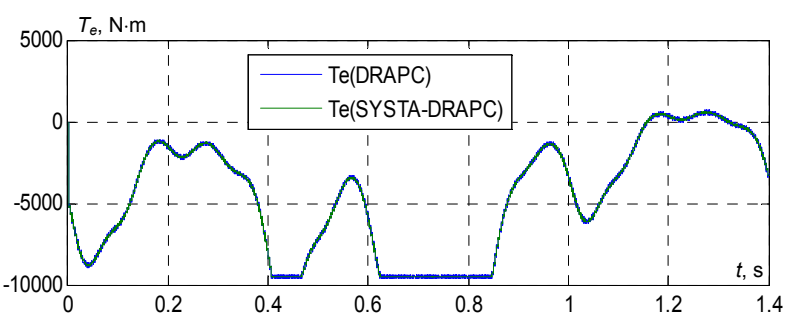

Fig. 9. Torque $T_{e}$

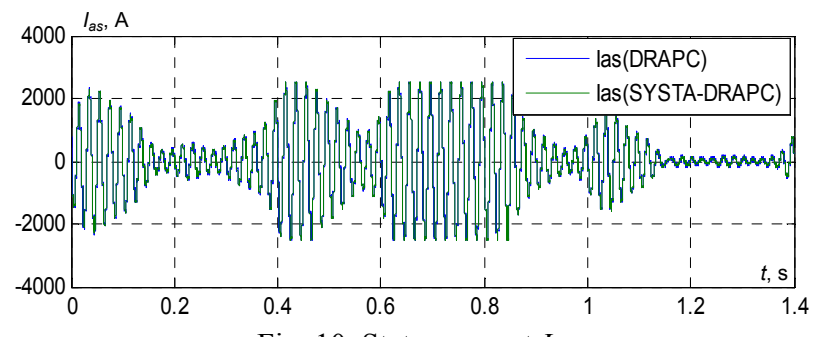

Fig. 10. Stator current $I_{a s}$

The zoom in the current, torque, reactive power, and active power is shown in Fig. 13-16, respectively. It can be seen that the proposed strategy minimized the 
undulations in current, torque, reactive power, and active power compared to the classical strategy.

Figures 17, 18 show the THD value of the current of both DRAPC strategies. It can be seen through these Figures that the THD value is reduced for the SYSTADRAPC $(0.19 \%)$ when compared to the classical DRAPC method $(1.08 \%)$. On the other hand, this designed strategy minimized the THD value of current compared to other strategies (see Table 2). Based on the results above, it can be said that the SYSTA-DRAPC strategy has proven its efficiency in minimizing undulations and chattering phenomena in addition to keeping the same advantages of the classical DRAPC strategy.

Table 2

Compare results with other methods

\begin{tabular}{|c|l|c|}
\hline & \multicolumn{1}{|c|}{ Method Name } & $\begin{array}{c}\text { THD } \\
(\%)\end{array}$ \\
\hline Ref. [37] & Field Oriented Control FOC & 3.7 \\
\hline \multirow{2}{*}{ Ref.[38] } & Direct Power Control DPC & 4.88 \\
\cline { 2 - 3 } & $\begin{array}{l}\text { Virtual-Flux Direct Power Control } \\
\text { VFDPC }\end{array}$ & 4.19 \\
\hline Ref. [39] & Sliding Mode Control SMC & 3.05 \\
\hline \multirow{2}{*}{ Ref. [40] } & $\begin{array}{l}\text { Second Order Continuous Sliding Mode } \\
\text { - Direct Torque Control SOCSM-DTC }\end{array}$ & 0.98 \\
\hline $\begin{array}{c}\text { Proposed } \\
\text { strategy }\end{array}$ & DRAPC & 1.08 \\
\cline { 2 - 3 } & SYSTA-DRAPC & 0.19 \\
\hline
\end{tabular}

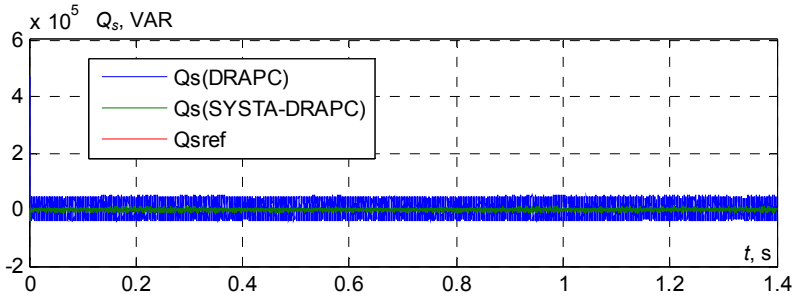

Fig. 11. Reactive power $Q_{s}$

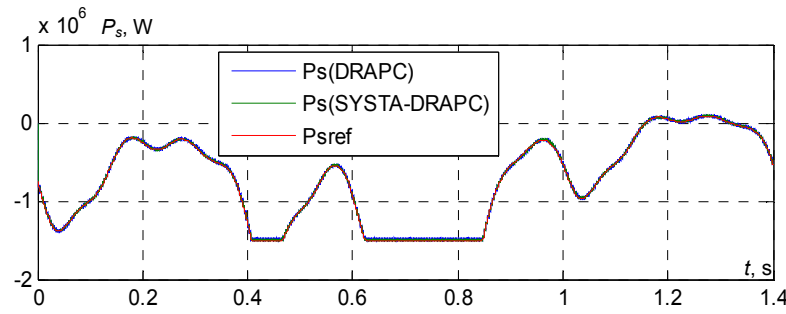

Fig. 12. Active power $P_{s}$

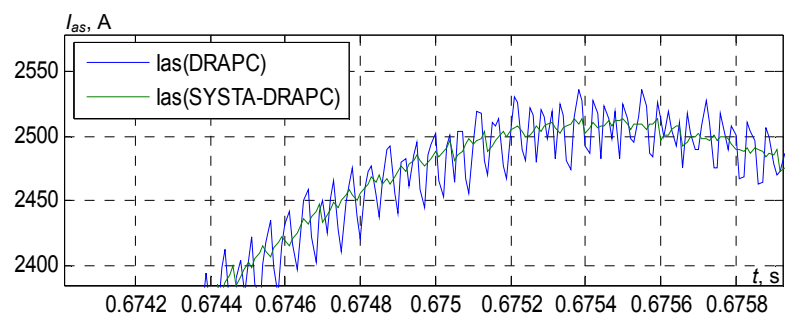

Fig. 13. Zoom of stator current $I_{a s}$

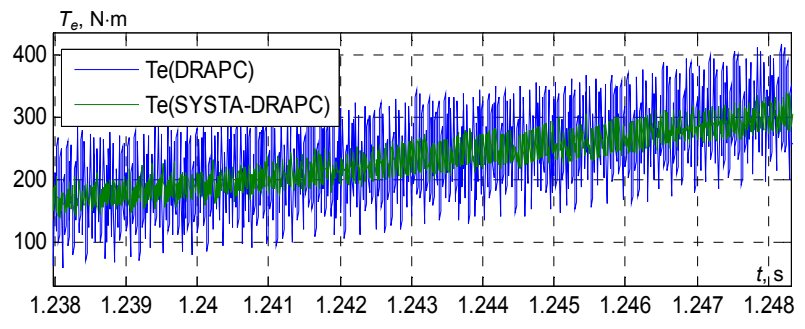

Fig. 14. Zoom of torque $T_{e}$

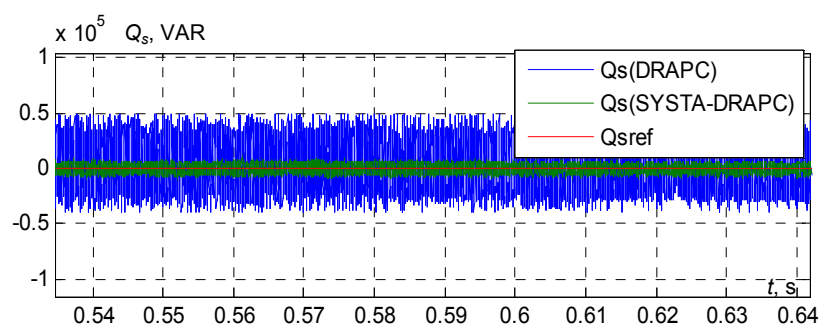

Fig. 15. Zoom of reactive power $Q_{s}$
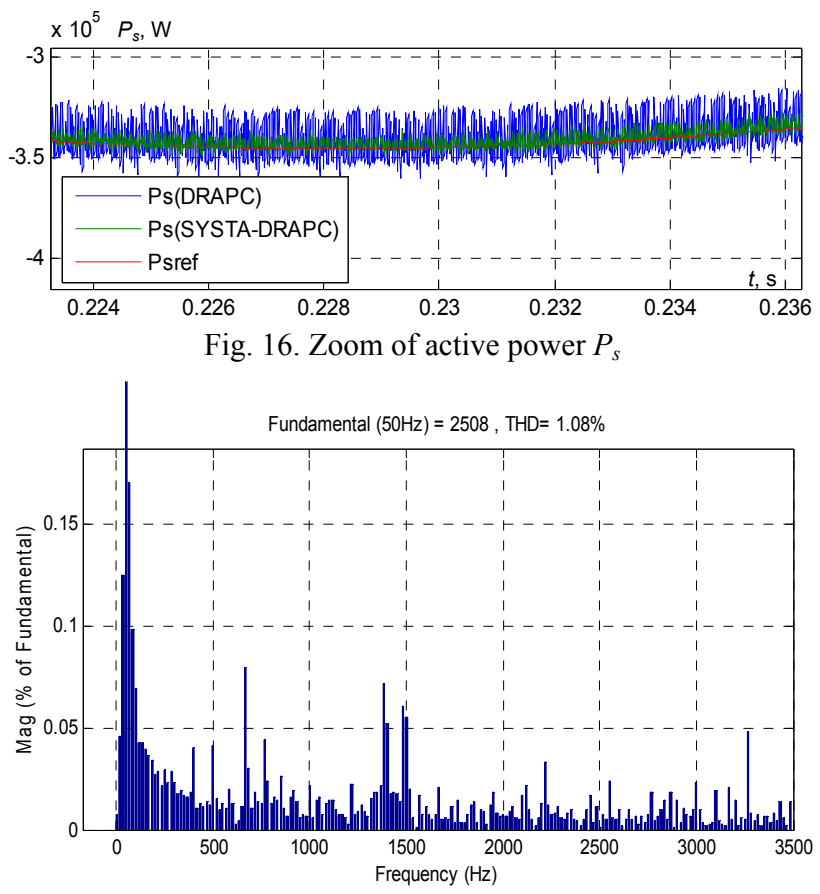

Fig. 17. THD of DRAPC method

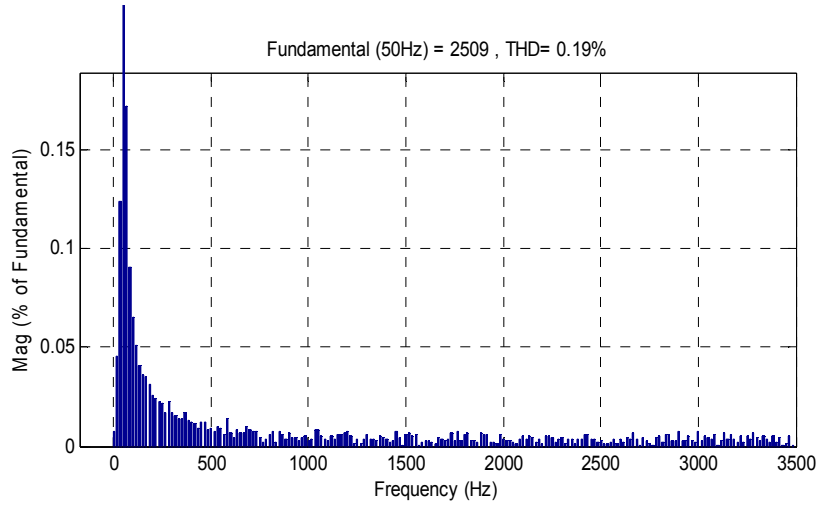

Fig. 18. THD of SYSTA-DRAPC method

B. Second test. In this test, we changed the values of both $L_{s}, L_{r}, R_{s}, R_{r}$ and $M$, in order to find out which method is not affected by a change of parameters. The results obtained are shown in Fig. 19-24. Note that there is a change in reactive power, torque, active power, and current due to the fact that both torque and current are related to the changing values of parameters. On the other hand, the classical method was greatly affected by the change of parameters compared to the designed technique (Fig. 25-28), and this is evident in the value of THD (Fig. 19-20). Thus it can be concluded that the DRAPC with proposed SYSTA controllers is more robust than the traditional DRAPC technique. 


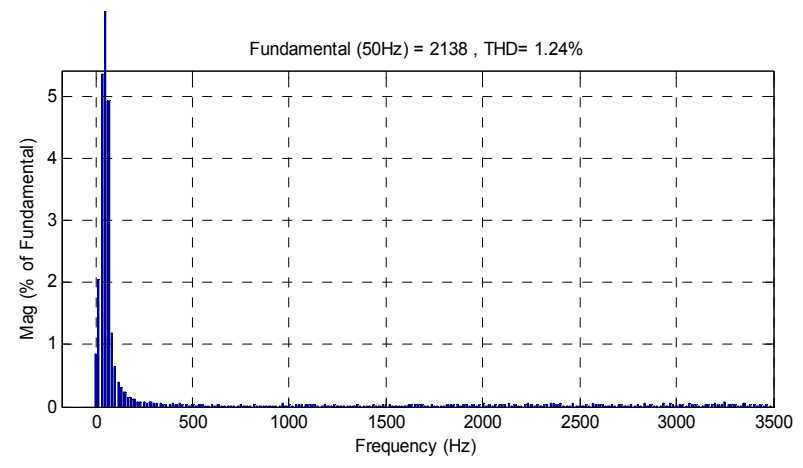

Fig. 19. THD of DRAPC method

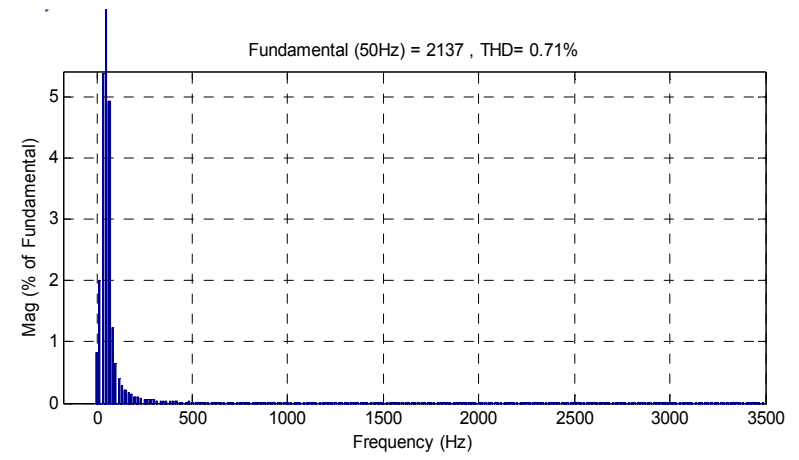

Fig. 20. THD of SYSTA-DRAPC method

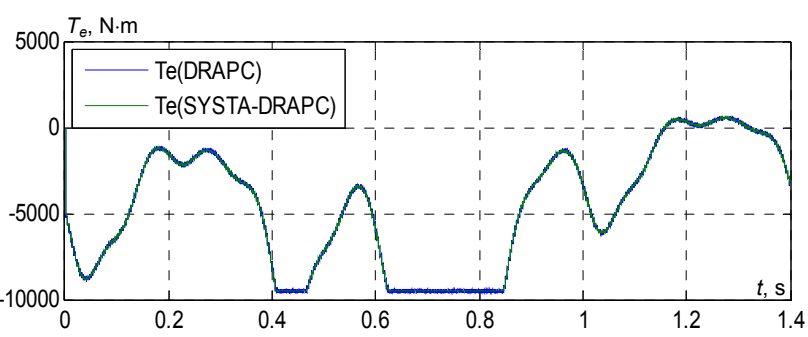

Fig. 21. Torque $T_{e}$

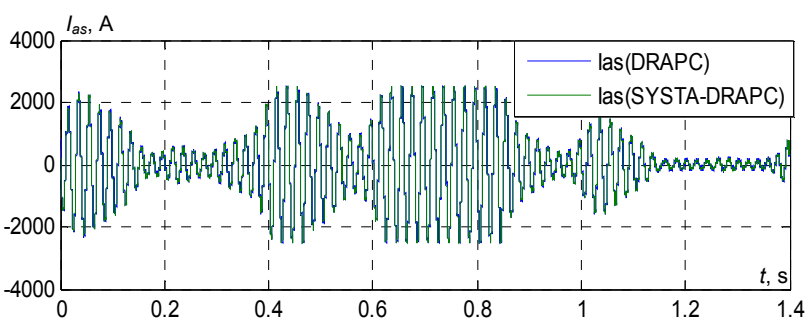

Fig. 22. Stator current $I_{a s}$

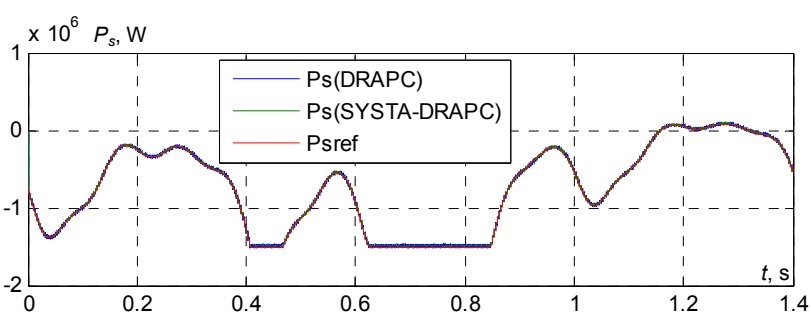

Fig. 23. Active power $P_{s}$

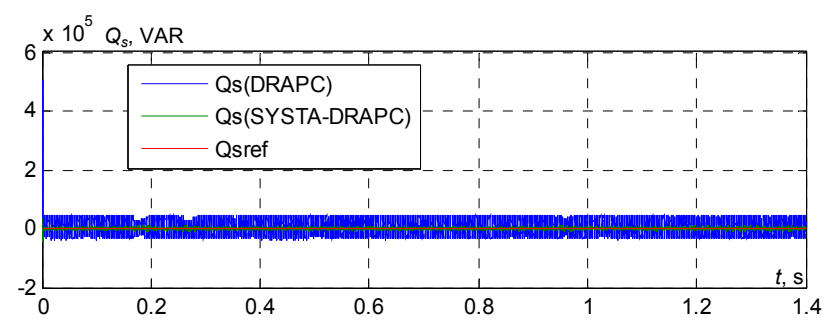

Fig. 24. Reactive power $Q_{s}$

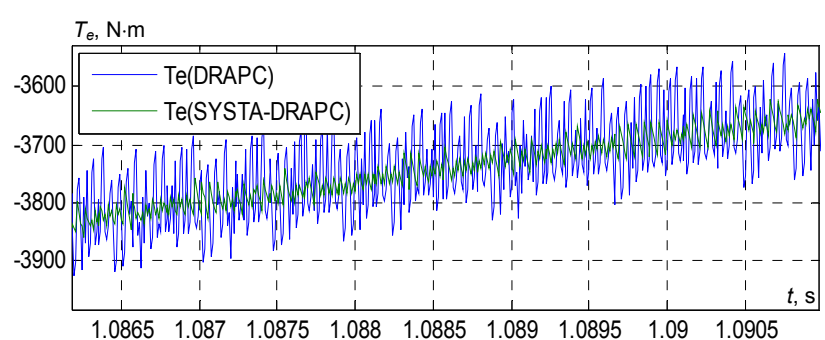

Fig. 25. Zoom of torque $T_{e}$

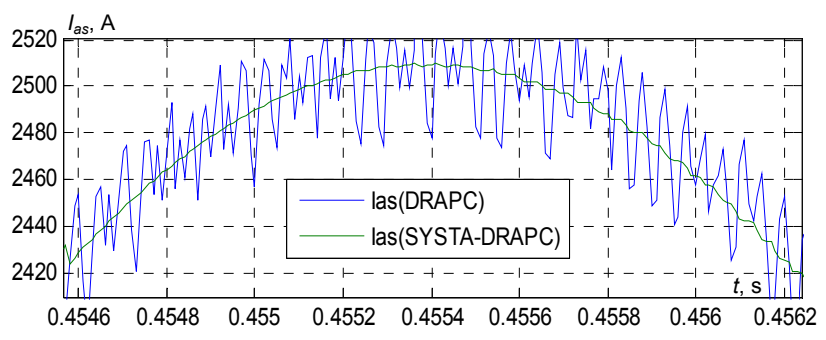

Fig. 26. Zoom of stator current $I_{a s}$

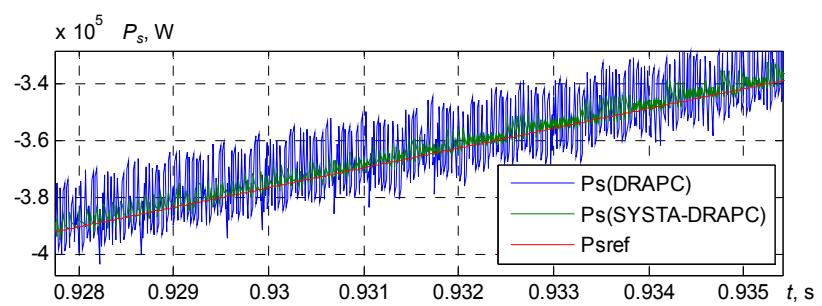

Fig. 27. Zoom of active power $P_{s}$

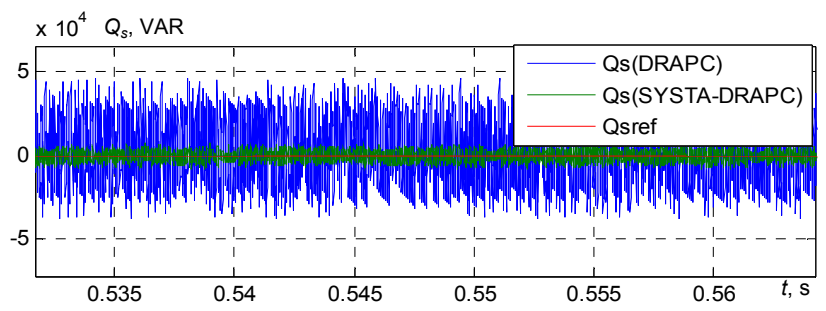

Fig. 28. Zoom of reactive power $Q_{s}$

\section{Conclusions.}

In this work, a novel nonlinear command theory for an asynchronous generator was designed based on a synergetic-super twisting algorithm. This command algorithm technique was employed to command the reactive and active powers of the asynchronous generator. The results indicated that the characteristics of the system had improved by using the synergetic-super twisting controllers and that this method could be applied to all electrical generators without exception. This is due to the results obtained. This designed method is easy to apply and does not require any effort, unlike other methods, where it requires mathematical calculations such as sliding mode control and backstepping command, and it is likely has a future in generating electrical energy using electric generators.

Conflict of interest. The authors declare that they have no conflicts of interest.

\section{REFERENCES}

1. Klimann A. H. R. The asynchronous generator: Mirage in electrical engineering. Proceedings of the IEEE, 1978, vol. 66, no. 8, pp. 986-986. doi: https://doi.org/10.1109/proc.1978.11064.

2. Benbouhenni H., Boudjema Z. Two-level DTC based on ANN controller of DFIG using 7-level hysteresis command to 
reduce flux ripple comparing with traditional command. 2018 International Conference on Applied Smart Systems (ICASS), 2018, pp. 1-8. doi: https://doi.org/10.1109/icass.2018.8652013. 3. Hamed H. A., Abdou A. F., Moursi M. S. E., EL-Kholy E. E. A modified DPC switching technique based on optimal transition route for of 3L-NPC converters. IEEE Transactions on Power Electronics, 2018, vol. 33, no. 3, pp. 1902-1906. doi: https://doi.org/10.1109/tpel.2017.2743230.

4. Xiong P., Sun D. Backstepping-based DPC strategy of a wind turbine-driven DFIG under normal and harmonic grid voltage. IEEE Transactions on Power Electronics, 2016, vol. 31, no. 6, pp. 4216-4225. doi: https://doi.org/10.1109/tpel.2015.2477442.

5. Jayachandra B., Mahesh A. ANN based direct power control of 2-level PWM rectifier. 2018 International Conference on Power Energy, Environment and Intelligent Control (PEEIC), 2018, pp. 623-627. doi: https://doi.org/10.1109/peeic.2018.8665617.

6. Lamterkati J., Khaffalah M., Ouboubker L., El afia A. Fuzzy logic based improved direct power control of three-phase PWM rectifier. 2016 International Conference on Electrical and Information Technologies (ICEIT), 2016, pp. 125-130. doi: https://doi.org/10.1109/eitech.2016.7519575.

7. Benbouhenni H. Application of five-level NPC inverter in DPC-ANN of doubly fed induction generator for wind power generation systems. International Journal of Smart Grid, 2019, vol. 3, no. 3, pp. 128-137. Available at: https://www.ijsmartgrid.org/index.php/ijsmartgridnew/article/vi ew/66/pdf (accessed 12 May 2020).

8. Amrane F., Chaiba A. A novel direct power control for gridconnected doubly fed induction generator based on hybrid artificial intelligent control with space vector modulation. Revue Roumaine des sciences techniques. Série Électrotechnique et Énergétique, 2016, vol. 61, no. 3, pp. 263-268. Available at: http://revue.elth.pub.ro/index.php?action=details\&id=597

(accessed 12 May 2020).

9. Huang J., Zhang A., Zhang H., Ren Z., Wang J., Zhang L., Zhang C. Improved direct power control for rectifier based on fuzzy sliding mode. IEEE Transactions on Control Systems Technology, 2014, vol. 22, no. 3, pp. 1174-1180. doi: https://doi.org/10.1109/tcst.2013.2273368.

10. Heydari E., Rafiee M., Pichan M. Fuzzy-genetic algorithmbased direct power control strategy for DFIG. Iranian Journal of Electrical and Electronic Engineering, 2018, vol. 14, no. 4, pp. 353-361. doi: http://dx.doi.org/10.22068/IJEEE.14.4.353.

11. Benbouhenni H. Synergetic control theory scheme for asynchronous generator based dual-rotor wind power. Journal of Electrical Engineering, Electronics, Control and Computer Science, 2021, vol. 7, no. 3, pp. 19-28. Available at: https://jeeeccs.net/index.php/journal/article/view/215/173 (accessed 12 May 2020).

12. Yaichi I., Semmah A., Wira P., Djeriri Y. Super-twisting Sliding Mode Control of a Doubly-fed Induction Generator Based on the SVM Strategy. Periodica Polytechnica Electrical Engineering and Computer Science, 2019, vol. 63, no. 3, pp. 178-190. doi: https://doi.org/10.3311/PPee.13726.

13. Benbouhenni H. A comparative study between NSMC and NSOSMC strategy for a DFIG integrated into wind energy system. Carpathian Journal of Electronic and Computer Engineering, 2019, vol. 12, no. 1, pp. 1-8. doi: https://doi.org/10.2478/cjece-2019-0001.

14. Levant A. Higher-order sliding modes, differentiation and output-feedback control. International Journal of Control, 2003, vol. 76, no. 9-10, pp. 924-941. doi: https://doi.org/10.1080/0020717031000099029.

15. Benbouhenni H. A comparative study between DTCNSTMC and DTC-FSTSMC control scheme for a DFIG-based wind turbine. Majlesi Journal of Energy Management, 2018, vol. 7 , no. 4, pp. 43-53. Available at: http://journals.iaumajlesi.ac.ir/em/index/index.php/em/article/vi ew/370 (accessed 12 May 2020).

16. Benbouhenni H., Boudjema Z., Belaidi A. DPC based on ANFIS super-twisting sliding mode algorithm of a doubly-fed induction generator for wind energy system. Journal Européen des Systèmes Automatisés, 2020, vol. 53, no. 1, pp. 69-80. doi: https://doi.org/10.18280/jesa.530109.

17. Benbouhenni H., Boudjema Z., Belaidi A. Direct power control with NSTSM algorithm for DFIG using SVPWM technique. Iranian Journal of Electrical \& Electronic Engineering, 2021, vol. 17, no. 1, pp. 1-11. doi: http://dx.doi.org/10.22068/IJEEE.17.1.1518.

18. Listwan J. Application of super-twisting sliding mode controllers in direct field-oriented control system of six-phase induction motor: experimental studies. Power Electronics and Drives, 2018, vol. 3, no. 1, pp. 23-34. doi: https://doi.org/10.2478/pead-2018-0013.

19. Gonzalez T., J Moreno. A., Fridman L. Variable gain supertwisting sliding mode control. IEEE Transactions on Automatic Control, 2012, vol. 57, no. 8, pp. 2100-2105. doi: https://doi.org/10.1109/tac.2011.2179878.

20. Qian J., Li K., Wu H., Yang J., Li X. Synergetic control of grid-connected photovoltaic systems. International Journal of Photoenergy, 2017, vol. 2017, pp. 1-11. doi: https://doi.org/10.1155/2017/5051489.

21. Kondratiev I., Dougal R., Veselov G., Kolesnikov A. Hierarchical control for electromechanical systems based on synergetic control theory. 2009 IEEE Control Applications, (CCA) \& Intelligent Control, (ISIC), 2009, pp. 495-500. doi: https://doi.org/10.1109/cca.2009.5280959.

22. Benbouhenni H., Zinelaabidine B., Abdelkader B. Comparison study between neural STSM and ANFIS-STSM method in DPC control scheme of DFIG-based dual-rotor wind turbines. International Journal of Energy and Environment, 2020, vol. 14, pp. 33-46. doi: https://doi.org/10.46300/91012.2020.14.7.

23. Yahdou A., Hemici B., Boudjema Z. Second order sliding mode control of a dual-rotor wind turbine system by employing a matrix converter. Journal of Electrical Engineering, 2016, vol. 16, no. 3, pp. 89-99. Available at: http://jee.ro/articles/WO1439151618W55c7b6024978d.pdf (accessed 12 May 2020).

24. Yahdou A., Djilali A.B., Boudjema Z., Mehedi F. Improved vector control of a counter-rotating wind turbine system using adaptive backstepping sliding mode. Journal Européen des Systèmes Automatisés, 2020, vol. 53, no. 5, pp. 645-651. doi:https://doi.org/10.18280/jesa.530507.

25. Benbouhenni H. ANFIS-sliding mode control of a DFIG supplied by a two-level SVPWM technique for wind energy conversion system. International Journal of Applied Power Engineering, 2020, vol. 9, no. 1, pp. 36-47. doi: https://doi.org/10.11591/ijape.v9.i1.pp36-47.

26. Berkane S., Tayebi A. Construction of synergistic potential functions on $\mathrm{SO}(3)$ with application to velocity-free hybrid attitude stabilization. IEEE Transactions on Automatic Control, 2017, vol. 62, no. 1, pp. 495-501. doi: https://doi.org/10.1109/tac.2016.2560537.

27. Butt R. S., Ahmad I., Iftikhar R., Arsalan M. Integral backstepping and synergetic control for tracking of infected cells during early antiretroviral therapy. IEEE Access, 2019, vol. 7, pp. 69447-69455. doi: https://doi.org/10.1109/access.2019.2907201.

28. Prasad R., Padhy N. P. Synergistic frequency regulation control mechanism for DFIG wind turbines with optimal pitch dynamics. IEEE Transactions on Power Systems, 2020, vol. 35, no. 4, pp. 3181-3191. doi: https://doi.org/10.1109/tpwrs.2020.2967468.

29. Ettouil R., Chabir K., Abdelkrim M. N. Optimal synergetic control for wind turbine system. The International Journal of Engineering and Science, 2018, vol. 7, no. 5, pp. 44-48. doi: https://doi.org/10.9790/1813-0705014448. 
30. Benbouhenni H. Rotor flux and torque ripples minimization for direct torque control of DFIG by NSTSM algorithm. Majlesi Journal of Energy Management, 2018, vol. 7, no. 3, pp. 1-9. Available

http://journals.iaumajlesi.ac.ir/em/index/index.php/em/article/vi ew/369 (accessed 12 May 2020).

31. Benbouhenni H. Twelve sectors DPC control based on neural hysteresis comparators of the DFIG integrated to wind power. Tecnica Italiana-Italian Journal of Engineering Science, 2020, vol. 64, no. 2-4, pp. 347-353. doi: https://doi.org/10.18280/ti-ijes.642-433.

32. Shah A. P., Mehta A. J. Direct power control of DFIG using super-twisting algorithm based on second-order sliding mode control. 2016 14th International Workshop on Variable Structure Systems (VSS), 2016, pp. 136-141. doi: https://doi.org/10.1109/vss.2016.7506905.

33. Malinowski M., Jasinski M., Kazmierkowski M. P. Simple direct power control of three-phase PWM rectifier using spacevector modulation (DPC-SVM). IEEE Transactions on Industrial Electronics, 2004, vol. 51, no. 2, pp. 447-454. doi: https://doi.org/10.1109/tie.2004.825278.

34. Benbouhenni H., Boudjema Z., Belaidi A. Power control of DFIG in WECS using DPC and NDPC-NPWM methods. Mathematical Modelling of Engineering Problems, 2020, vol. 7 , no. 2, pp. 223-236. doi: https://doi.org/10.18280/mmep.070208. 35. Gong B., Wang K., Meng F., You J., Y Luo. A comparative study on switching tables of direct power control for voltage source rectifier. 2014 IEEE International Conference on Mechatronics and Automation, 2014, pp. 1978-1983. doi: https://doi.org/10.1109/icma.2014.6886006.

36. Benbouhenni H. Sliding mode with neural network regulator for DFIG using two-level NPWM strategy. Iranian Journal of Electrical \& Electronic Engineering, 2019, vol. 15, no. 3, pp. 411-419. doi: http://dx.doi.org/10.22068/IJEEE.15.3.411.

37. Amrane F., Chaiba A., Badr Eddine B., Saad M. Design and implementation of high performance field oriented control for grid-connected doubly fed induction generator via hysteresis rotor current controller. Revue Roumaine des sciences techniques. Série Électrotechnique et Énergétique, 2016, vol. 61, no. 4, pp. 319-324. Available at: http://revue.elth.pub.ro/index.php?action $=$ details\&id $=609$ (accessed 12 May 2020).

38. Yusoff N. A., Razali A. M., Karim K. A., Sutikno T., Jidin A. A concept of virtual-flux direct power control of three-phase AC-DC converter. International Journal of Power Electronics and Drive System, 2017, vol. 8, no. 4, pp. 1776-1784. doi: http://doi.org/10.11591/ijpeds.v8.i4.pp1776-1784.

39. Boudjema Z., Meroufel A., Djerriri Y., Bounadja E. Fuzzy sliding mode control of a doubly fed induction generator for energy conversion. Carpathian Journal of Electronic and Computer Engineering, 2013, vol. 6, no. 2, pp. 7-14. Available at: http://cjece.ubm.ro/vol/6-2013/202-6117.pdf (accessed 12 May 2020).

40. Boudjema Z., Taleb R., Djerriri Y., Yahdou A. A novel direct torque control using second order continuous sliding mode of a doubly fed induction generator for a wind energy conversion system. Turkish Journal of Electrical Engineering \& Computer Sciences, 2017, vol. 25, no.2, pp. 965-975. doi: https://doi.org/10.3906/elk-1510-89.

Received 18.03.2021

Accepted 28.04.2021

Published 25.06.2021

Habib Benbouhenni ${ }^{1}$, Doctor of Electrical Engineering,

Soufiane Lemdani $i^{2}$, Doctor of Electrical Engineering,

${ }^{1}$ Department of Electrical \& Electronics Engineering,

Nisantasi University, Istanbul, Turkey,

e-mail: habib.benbouenni@nisantasi.edu.tr (Corresponding

author)

${ }^{2}$ Department of Electrical Engineering,

University of Science and Technology of Oran-Mohamed-

Boudiaf, Oran, Algeria,

e-mail: lamdaniso@yahoo.fr

How to cite this article:

Benbouhenni H., Lemdani S. Combining synergetic control and super twisting algorithm to reduce the active power undulations of doubly fed induction generator for dual-rotor wind turbine system. Electrical Engineering \& Electromechanics, 2021, no. 3, pp. 8-17. doi: https://doi.org/10.20998/2074-272X.2021.3.02. 